\title{
Mulheres soropositivas para o HIV e seus companheiros frente à decisão pela gestação
}

\author{
HIV seropositive women and their partners facing the decision of a pregnancy \\ Mujeres seropositivas para el VIH y sus parejas frente a la decisión del embarazo
}

\section{Fernanda Peixoto Cordova', Anna Maria Hecker Luz", Agnes Peruzzo Innocente ${ }^{\mathrm{III}}$, Eveline Franco da Silva ${ }^{\mathrm{IV}}$}
' Universidade Federal do Rio Grande do Sul, Hospital de Clínicas de Porto Alegre. Porto Alegre-RS, Brasil.
"Universidade do Vale do Rio dos Sinos, Curso de Enfermagem. São Leopoldo-RS, Brasil.
II'Centro Universitário Metodista IPA, Curso de Enfermagem (Graduanda). Porto Alegre-RS, Brasil.
Iv Universidade Federal do Rio Grande do Sul, Programa de Pós-Graduação em Enfermagem (Mestranda).
Porto Alegre-RS, Brasil.

Submissão: 16-09-2011 Aprovação: 10-02-2013

\section{RESUMO}

Estudo exploratório descritivo, com abordagem qualitativa, que objetivou investigar os motivos que levam mulheres soropositivas para o HIV e seus companheiros a decidirem engravidar, tendo em vista o risco da transmissão vertical e da contaminação ou reinfecção do parceiro. Participaram do estudo seis gestantes. A coleta de dados foi realizada por questionário semiestruturado, sendo os dados organizados no software NVivo 2.0 e interpretados por meio da análise de conteúdo do tipo temática. Da análise emergiram três temas: Planejamento da Gravidez; Conhecimento sobre Transmissão e Tratamento do HIV/AIDS; Vivendo no Contexto HIV/AIDS. A importância do estudo reside no fato de que, apesar do risco da transmissão vertical e da contaminação do parceiro ser conhecido pelo casal, isto não interfere no desejo de serem pais.

Descritores: Sorodiagnóstico da AIDS; Doença Sexualmente Transmissível; Gestantes, Pesquisa Qualitativa; Síndrome da Imunodeficiência Adquirida.

\begin{abstract}
The purpose of this qualitative, descriptive exploratory study is to investigate the reasons why HIV seropositive women and their partners make the decision of becoming pregnant despite the risk of vertical transmission, contamination or reinfection of the partner. The subjects of this study were six pregnant women. Data collection was done through a semi-structured questionnaire which was organized in the NVIVO 2.0 software and interpreted through theme-based content analysis. Through this analysis three themes emerged: Pregnancy planning; Knowledge of HIV/AIDS transmission and treatment; Living in the context of HIV/ AIDS. The relevance of this study resides on the fact that the desire of the couple in becoming parents remains, despite of the awareness regarding the risks of vertical transmission and contamination.
\end{abstract}

Key words: AIDS Serodiagnosis; Sexually Transmitted Diseases; Pregnant Women; Qualitative Research; Acquired Immunodeficiency Syndrome.

\section{RESUMEN}

Estudio exploratorio descriptivo con abordaje de tipo cualitativo, cuyo objetivo fue investigar las razones por qué las mujeres VIH positivas y sus parejas deciden por el embarazo dado el riesgo de transmisión vertical, infección o reinfección de la pareja. Los participantes fueron seis mujeres embarazadas. La recolección de datos se realizó mediante un cuestionario semiestructurado, con datos organizados en el software NVivo 2,0 y interpretados por intermedio del análisis de contenido temático. El análisis reveló tres temas: Planificación del embarazo; Conocimiento sobre la transmisión y tratamiento del VIH / SIDA; Vivir en el contexto del VIH/SIDA. La importancia del estudio radica en el hecho de que a pesar del riesgo de transmisión vertical y la contaminación de la pareja ser conocida por la pareja, esto no interfiera con el deseo de ser padres.

Palabras clave: Serodiagnóstico del SIDA; Enfermedades de Transmisión Sexual; Mujeres Embarazadas; Investigación Cualitativa; Síndrome de Inmunodeficiencia Adquirida.

\section{AUTOR CORRESPONDENTE Fernanda Peixoto Cordova E-mail: fpcordova@terra.com.br}




\section{INTRODUÇÃO}

A epidemia da AIDS surgiu no Brasil na década de 1980 e, apesar de ter surpreendido a sociedade pode-se dizer que foi este país que agiu mais rapidamente, em comparação aos países atingidos, na redução da transmissão e dos agravos da doença ${ }^{(1)}$.

Segundo dados do Boletim Epidemiológico DST/AIDS, a situação desta epidemia é considerada estável, mesmo que o percentual de notificações da doença permaneça elevado nas regiões Sudeste $(60 \%)$ e Sul $(18,9 \%)$. Na região Sul, a incidência da AIDS aumentou de $26,3 \%$ para $28,3 \%$ no período de 2000 a 2006, tendo maior índice de infecção no ano de $2002^{(2)}$.

Ao se analisar a distribuição do HIV/AIDS segundo sexo e idade, no Brasil, a razão de homens infectados para cada muIher infectada que, em 1983, era de 40 homens, hoje passa a ser de $1,3^{(2)}$, fenômeno denominado processo de feminização da $\operatorname{AIDS}^{(1,3)}$.

Em relação ao modo de contágio, para indivíduos com até 13 anos de idade é a transmissão vertical; para os com mais de 13 anos, é a relação heterossexual, para as mulheres, e a relação heterossexual seguida da homossexual para os homens ${ }^{(2)}$.

No recorte por sexo e faixa etária, o maior número de muIheres infectadas está na faixa de 20 a 49 anos $^{(2)}$. Tal fato tem contribuído para a transmissão vertical, considerada como umas das consequências mais dramática do envolvimento da mulher na epidemia ${ }^{(3)}$.

Essa alta incidência entre as mulheres está relacionada a fatores biológicos, culturais e socioeconômicos. Além disso, elas "têm pouco ou nenhum controle quanto às decisões relativas a quando e sob quais condições ter relação sexual, ao uso do condom pelo parceiro e, menos ainda, das condutas sexuais dele"(4).

Nesse contexto, observa-se na literatura e no Programa de Prevenção ao HIV/AIDS a ênfase às formas de prevenção, uso de preservativo, sem considerar a situação destacada anteriormente nem, tampouco, abordar satisfatoriamente questões relacionadas às medidas específicas de anticoncepção ${ }^{(3)}$. Esse fenômeno, portanto, parece indicar que os serviços de saúde e a produção científica sobre a temática ainda não consideram que a contaminação pelo HIV e a gravidez podem ocorrer na mesma relação sexual, o que aponta a necessidade de se lançar um olhar especial sobre esse campo.

Pesquisa realizada em São Paulo com objetivo de estudar a sexualidade e a saúde reprodutiva das mulheres HIV positivas evidenciou que mulheres soropositivas para HIV, principalmente as mais jovens, desejam ter filhos, mesmo cientes do risco da contaminação vertical e/ou do seu companheiro; que houve falta de informação em relação ao melhor método contraceptivo a ser utilizado; e que a maioria delas gostaria de discutir questões sobre sexualidade com seus médicos clínicos em função do vínculo já estabelecido ${ }^{(5)}$. Outra pesquisa realizada em São Paulo identificou forte desejo pela maternidade entre as mulheres soropositivas ${ }^{(3)}$.

Esse desejo provavelmente se refere ao reconhecimento de que maternidade e paternidade são momentos importantes na vida do homem e da mulher e que podem Ihes propiciar integração social e desenvolvimento da personalidade. Isto porque o viver em família permite entender o significado da herança cultural e dos valores da sociedade, e um filho pode dar continuidade à existência dos pais, propiciar novos significados à vida do casal, principalmente aos que vivem em situação de contaminação pelo HIV/AIDS ${ }^{(6-7)}$.

É fundamental, portanto, que homens e mulheres com HIV/ AIDS possam exercer seus desejos e direitos sexuais e reprodutivos. Porém, cabe aos serviços e profissionais da saúde discutir com os casais como fazer isso. Para tal, aponta-se necessidade de incorporar ações para apoiar os casais sorodiscordantes ou soroconcordantes para o HIV, com base na Política de Planejamento Familiar desenvolvida pelo Ministério da Saúde, estimulando-os a praticar sexo seguro, a enfrentar os conflitos de querer ter filhos e a fazer escolhas consentidas e informadas ${ }^{(5,8)}$.

Nesse sentido, é preciso que os profissionais da saúde compreendam os reais motivos que levam homens e mulheres a optarem por ter filhos, pois, mesmo que haja um efetivo programa de prevenção da transmissão vertical, ainda não se tem dado suficiente aporte aos casais soropositivos para tomada de decisões conscientes ${ }^{(5)}$.

Frente a tal contexto, o objetivo desta pesquisa é investigar os motivos que levam mulheres soropositivas para o HIV e seus companheiros a decidirem engravidar, tendo em vista o risco da transmissão vertical e da contaminação ou reinfecção do parceiro.

\section{METODOLOGIA}

O estudo foi exploratório-descritivo, com abordagem qualitativa, e buscou explorar e conhecer melhor o fenômeno ${ }^{(9)}$ da decisão pela gestação de casais soropositivos para o HIV.

A pesquisa foi realizada com mulheres do Serviço de Atendimento Especializado em Doenças Sexualmente Transmissíveis - DST/AIDS da Secretaria Municipal de Saúde de Porto Alegre. Os critérios para participar da pesquisa foram: ser gestante, ter dezoito anos completos e saber do diagnóstico do HIV antes de engravidar.

Nesse serviço, no período de coleta (fevereiro a abril de 2010), o número de gestantes em acompanhamento era 36 e, destas, apenas 15 atendiam aos critérios de inclusão estabelecidos. Participaram dessa pesquisa seis mulheres que integravam o grupo semanal de gestantes. Não foi possível incluir outras gestantes, pois, no período da coleta, em algumas ocasiões não houve reunião com o grupo de gestantes, impossibilitando o acesso às mesmas.

Para coleta de informações utilizou-se questionário semiestruturado, contemplando dados de identificação da mulher e de seu companheiro, questões dos motivos pela decisão em gestar e das percepções da mulher em relação a si e ao seu companheiro frente à gestação e o risco da transmissão vertical e reinfecção do parceiro.

As informações foram analisadas mediante técnica de análise de conteúdo do tipo temática, a qual se estrutura na ordenação das informações, classificação das informações e análise final( ${ }^{(9)}$. Na fase de organização e tratamento das informações foi utilizado o software NVivo 2.0, programa que auxilia na 
análise de material qualitativo, com ferramentas de codificação e armazenamento de textos em categorias específicas ${ }^{(10)}$.

A pesquisa contemplou diretrizes e normas regulamentadoras de pesquisas envolvendo seres humanos, sendo submetida ao Comitê de Ética em Pesquisa da Secretaria Municipal de Saúde de Porto Alegre, com Parecer no 405, de 27 de outubro de 2009, favorável a sua realização.

As mulheres foram informadas sobre o objetivo da pesquisa e aquelas que aceitaram participar assinaram o Termo de Consentimento Livre e Esclarecido. $\mathrm{O}$ anonimato foi preservado pela representação do nome das mulheres por Q1, Q2, Q3..., conforme ordem de resposta.

\section{RESULTADOS E DISCUSSÃO}

A idade das mulheres participantes da pesquisa variou entre 26 e 33 anos, e a dos homens entre 28 e 36 anos. Quanto à escolaridade, quatro homens e quatro mulheres tinham ensino fundamental incompleto, uma tinha ensino fundamental completo, um homem e uma mulher tinham ensino médio completo, e uma delas desconhecia a escolaridade do companheiro. Em relação à infecção pelo HIV, todas as entrevistadas eram soropositivas, e quatro delas disseram que seus companheiros também eram soropositivos; uma não sabia se o companheiro era, pois ele nunca quis fazer o teste; e outra declarou que seu companheiro não tinha o vírus. O tempo de descoberta da infecção variou de 5 a 14 anos.

Em relação ao número de filhos, três mulheres tinham dois filhos; uma tinha cinco; e duas nenhum. Das mulheres com filhos, uma delas tinha um filho soropositivo.

Da análise dos questionários preenchidos pelas participantes do estudo emergiram três categorias temáticas: Planejamento da Gravidez; Conhecimento sobre Transmissão e Tratamento do HIV/AIDS; Vivendo no Contexto HIV/AIDS.

\section{A. Planejamento da gravidez}

A opção pela gestação é considerada uma das principais decisões reprodutivas que as mulheres tomam, diretamente influenciada, mesmo que em diferentes graus, por questões psicossociais e culturais ${ }^{(11,12)}$. Portanto, o fato de homem e mulher serem soropositivos para o HIV não diminui o desejo de terem filhos ${ }^{(13)}$. Os profissionais da saúde devem ter consciência de que, para esses casais, o estado sorológico poderá não ser considerado na tomada de decisão sobre gravidez, no uso de métodos contraceptivos e, tampouco, na opção por interrupção da gestação ${ }^{(11)}$.

Dentre as seis participantes, metade delas disse que seu companheiro e ela planejaram a gravidez (Q4, Q5 e Q6). Quando questionadas sobre o uso de método contraceptivo, declararam que faziam uso de pelo menos um, sendo mais citado o anticoncepcional oral (ACO). Apenas duas participantes informaram uso da camisinha masculina.

De acordo com a literatura, o uso de ACO deve ser cauteloso quando se trata de mulheres soropositivas para o HIV, pois, quando ocorre ingestão concomitante aos antirretrovirais, o efeito contraceptivo é reduzido, sendo mais indicado uso de preservativos masculinos ou femininos ${ }^{(3)}$.
Os que planejaram engravidar suspenderam uso do método contraceptivo, e apenas um casal foi orientado pelo médico sobre o melhor momento de engravidar, com base no acompanhamento sorológico.

[...] eu parei de tomar injeção e não usamos mais camisinha. (Q4)

[...] como eu e meu companheiro queria ter um filho, nós paramos de usar (camisinha). (Q6).

A gente conversou e achou que seria esse o momento já que eu ainda não tomo medicação, e o doutor falou que se eu quisesse ter um filho a hora era agora que os exames estavam bons. (Q5)

Considerando-se que apenas uma delas fez referência ao aconselhamento médico na decisão de engravidar, pode-se inferir que o dilema nas escolhas reprodutivas é que as mulheres soropositivas para o HIV e seus companheiros raramente conseguem discutir o assunto gestação com os profissionais de saúde que os acompanham, limitando a oportunidade de exercerem seus direitos sexuais e reprodutivos. Pesquisa realizada em São Paulo, citada anteriormente, revelou que muitas mulheres desconheciam o melhor método contraceptivo a ser utilizado e qual o melhor modo de engravidar, diminuindo, assim, o risco da transmissão vertical e de ocorrência de reinfecção da mãe ou do parceiro(5).

As mulheres que não planejaram a gravidez disseram que engravidaram em decorrência da perda do efeito do ACO, por estar fazendo tratamento para tuberculose; do esquecimento do uso do ACO; e de o parceiro não gostar de utilizar o preservativo.

Sim, eu tomava anticoncepcional, mas devido a outro tratamento feito para tuberculose ele não teve o mesmo efeito e aí engravidei. (Q1)

Usava preservativo, mas ele não gosta. Não usei por quatro dias e então engravidei. (Q2)

O fato de essas mulheres engravidarem sem planejamento demonstra, mais uma vez, que os serviços de saúde designados ao atendimento de pessoas portadoras de HIV ainda não conseguiram desenvolver um trabalho efetivo de auxílio às questões ligadas ao planejamento familiar, à sexualidade feminina na presença do HIV e aos direitos reprodutivos $^{(11)}$. Para as que decidiram engravidar, os motivos alegados foram por desejo de terem filhos, por seu companheiro ter filhos de outro relacionamento ou para ter companhia, alguém para amar.

Do nosso primeiro filho não planejamos, mas esse que eu estou esperando, nós queríamos muito. (Q4)

Ter uma companhia e alguém que eu amasse muito e retribuísse tudo isso. (Q6) 
Esses dados assemelham-se aos de outro estudo realizado com mulheres portadoras do $\operatorname{HIV} / A I D S^{(3,5,11)}$, no qual as razões das mesmas quererem engravidar foram: desejo de seus companheiros, por não terem acompanhado os filhos já tidos e por se sentirem mais completas e felizes. Essas mulheres, mesmo temendo pela sua saúde e a do bebê, não viam esses riscos como algo que diminuísse seu desejo, pois elas queriam dar um filho a seu companheiro e afirmaram que não permitiriam que a infecção pelo HIV/AIDS as impedisse.

Para as mulheres e homens que não planejaram a gestação, embora esta tenha ocorrido acidentalmente, os motivos alegados para não engravidar foram: em decorrência de ser portadora da doença, por já ter outros filhos e por não desejar mais filhos.

Não pretendíamos ter filhos por causa da doença e porque já tínhamos filhos de outros relacionamentos anteriores. (Q1)

\section{Meu marido não queria mais filhos. (Q3)}

No estudo de São Paulo, as razões alegadas pelas mulheres que não pensavam em ter filhos estavam mais relacionadas ao medo da doença para si e para sua criança do que a não ausência de filhos. Por outro lado, as mulheres que decidiram pela gestação tinham medo de que seus filhos nascessem com HIV e de não receber apoio da sociedade ${ }^{(5)}$.

Estudo realizado no Rio Grande do Sul, com o objetivo de investigar as percepções sobre a vivência conjugal de casais soro diferentes para o HIV, revelou que os motivos, por eles alegados, para não engravidarem estavam relacionados ao não querer filhos, não querer serem pais naquele momento ou já terem muitos filhos e por falta de condições financeiras para sustentar mais um ${ }^{(14)}$.

Com base nesses estudos, pode-se dizer que no contexto da infecção pelo HIV é muito comum a ambivalência dos casais em relação à decisão pela gestação, pois conhecem o risco da contaminação da criança e do parceiro(5).

\section{B. Conhecimento sobre transmissão e tratamento do HIV/ AIDS}

A partir do que as mulheres responderam neste estudo verifica-se que elas e seus companheiros sabem identificar o modo de transmissão do HIV e como deve ser o tratamento da AIDS.

Sobre transmissão: pelo contato sexual em geral sem preservativo, transfusão de sangue, da mãe para o nenê. (Q1)

Depois que se tem o vírus, o jeito é fazer tratamento direitinho para ter uma qualidade de vida melhor. (Q5)

No Brasil, mediante assistência à saúde de pacientes soropositivos para o HIV, procura-se divulgar e enfatizar as formas de prevenção, os modos de transmissão do vírus e o tratamento. Esse fato, possivelmente tem gerado maior grau de informação para a população sobre essas questões, conforme se observou nos depoimentos destacados.
Em relação ao cuidado para prevenir a transmissão vertical, as mulheres também demonstraram saber o que deve ser feito.

Sei que devo tomar medicação para não contaminar (o bebê). Devo tomar AZT até o parto, dar xarope para o bebê e não amamentar. (Q2)

Isto, possivelmente, também tem ocorrido em função de os serviços de saúde concentrarem seus esforços na aplicação do protocolo de profilaxia da transmissão vertical recomendado pelo Ministério da Saúde às gestantes e parturientes soropositivas.

A preocupação das mulheres com a transmissão vertical muito provavelmente esteja relacionada ao medo de contaminar o bebê por ocorrência da gestação e do parto:

[...] eu tenho medo que ele (bebê) se contamine, mas sigo o tratamento direitinho para que isso não venha a acontecer. (Q1)

Eu penso que meu bebê pode nascer com o vírus, mas eu vou fazer o que puder para ela negativar que nem minha outra filha. (Q3)

Percebe-se, nessas falas, a noção de autorresponsabilização, por parte das mulheres, pela não contaminação do seu bebê. Um estudo realizado com gestante soropositivas para o HIV, objetivando compreender de que modo a gestante portadora do vírus percebe sua corporeidade em um estar no mundo gerando outro ser, revelou que o sentimento de culpa causa sofrimento às gestantes e "a possibilidade de ter um filho doente gera um abalo em sua existência e influencia no seu estar no mundo"(15).

Para alguns autores ${ }^{(16)}$, a culpa por colocar o filho em risco, o medo de infectá-lo e de que ele possa morrer em consequência da infecção, contrasta com a concepção idealizada da maternidade, que dá à mulher a capacidade de gerar a vida e assumir um lugar social privilegiado. Contudo, considera-se que a presença ou a intensidade desses sentimentos está relacionada às ambivalências e paradoxos vividos por qualquer mulher, gerando sobrecargas particulares. Quanto ao risco de contaminação do companheiro, observa-se que na situação de sorodiscordância o casal se preocupa com essa possibilidade, buscando, de algum modo, minimizar os riscos, embora não abra mão do direito de gestar.

Sabemos dos riscos tanto com ele que não é portador quanto o bebê que pode ter. (Q4)

Já, em relação à reinfecção, quando os dois são portadores do vírus, esta parece não ser uma realidade conhecida ou preocupante entre os casais, pois as mulheres mencionaram o anticoncepcional como método contraceptivo, não citando o uso do preservativo.

\section{Vivendo no contexto HIV/AIDS}

As características da AIDS e o imaginário social construído em relação à epidemia de HIV/AIDS evidenciam seu 
impacto singular sobre a vida dos homens e das mulheres, especialmente no período de transição para a paternidade e a maternidade ${ }^{(16)}$.

Nesta pesquisa, são diversas as repercussões de viver com HIV/AIDS tanto para as mulheres quanto para seus companheiros. Para alguns, a vida parece ter se tornado um pouco mais sofrida; para outros, nem tanto.

Eu não me considero doente, mas tenho minhas tristezas. (Q1)

\section{[...] a pessoa tem que aceitar. (Q3)}

Representa uma vida quase normal porque se vive do mesmo jeito que antes, fazendo as mesmas coisas, só que [...] a partir do momento que temos o vírus, temos que planejar tudo o que vamos fazer, principalmente não descuidar do tratamento e de ter filhos sem acompanhamento médico. (Q5)

É preciso considerar o estigma social que associou o HIV/ AIDS a comportamentos considerados socialmente desviantes, e que o imaginário social relacionado à infecção ainda está impregnado pela noção ultrapassada de grupos de risco e por concepções erradas sobre as formas de contaminação. Esse estigma dificulta a adesão a comportamentos de prevenção e penaliza ainda mais os portadores do vírus, aumentando o preconceito $^{(16)}$.

Representa que as outras pessoas nos olham com ar de preconceito. (Q6)

Mesmo em tempos atuais, ainda é grande a possibilidade de o portador do vírus HIV sofrer discriminações por parte dos vizinhos e familiares. Esse preconceito faz com que as pessoas que vivem ou convivem com o HIV/AIDS se isolem e passem a ser alvo de recusa por parte da família e amigos ${ }^{(17)}$.

[...] de vez em quando me sinto muito só porque minha família não sabe da doença. (Q1)

Muitas vezes, também, a família do portador reproduz as metáforas negativas, a estigmatização e a discriminação construídas na sociedade, e isso estimula muitos portadores ao autoisolamento, reforçando a baixa adesão aos cuidados com a saúde com medo da discriminação, dentro e fora de casa. É comum se encontrar pessoas vivendo com HIV, sofrendo de isolamento social ${ }^{(7)}$, ou, no caso dos casais aqui pesquisados, podendo somente "contar um com o outro" (Q5).

Na situação de ser mãe soropositiva, a condição da não amamentação aparece como a principal dificuldade para a mulher.

Sei que não posso amamentar e tenho que ter uma série de cuidados com o bebê. (Q4)

Vou sentir falta de amamentar. (Q1)
[...] o pior é não poder amamentar. Me sinto muito mal não poder amamentar. Essa é a pior parte. Eu amamentei meu primeiro filho e sinto muita falta, gostava muito de dar de mamar. (Q2)

De acordo com a literatura, a amamentação parece trazer para a mulher portadora do HIV/AIDS dupla mensagem social. Enquanto a amamentação para mulheres hígidas é altamente estimulada pelos profissionais de saúde, no caso da infecção pelo HIV/AIDS ela é proibida. Nessa situação, o leite da muIher, por não ser considerado benéfico para a criança, pode despertar diversos sentimentos nas mães e repercutir na sua experiência de maternidade, pois a mulher sabe da importância do aleitamento materno para ela e seu filho e se vê impedida de amamentar ${ }^{(16)}$. Essa situação aponta para a necessidade de se construir estratégias que minimizem essa perda, preparando as gestantes soropositivas para enfrentar esse impedimento, tanto para si quanto perante a família e a sociedade.

Ser pai no contexto do HIV revelou-se, na percepção das mulheres, algo bastante singular. Algumas destacaram que para seus companheiros foi péssimo, principalmente quando a gestação não foi planejada. No entanto, nas situações de gestações planejadas, os companheiros demonstraram muita alegria.

Péssimo, sem total interesse, não conversamos sobre isso para não brigarmos. (Q1)

Ele está muito feliz porque ele já tem dois filhos que estão grandes. (Q5)

Ele sabe que um filho trará muita alegria para nós dois. (Q6)

Na gravidez, os casais podem sentir tanto sentimentos de alegria, tristeza, satisfação quanto de insatisfação. Para alguns, esse momento traz alegrias e o desejo de conviver harmoniosamente, e, para outros, os conflitos já vivenciados podem se acentuar $^{(18)}$. Considerando-se o contexto da HIV/AIDS, para os homens, correr o risco de ser pai de uma criança soropositiva, ser companheiro de uma mulher soropositiva e até mesmo correr o risco de infectar, parece também não ser uma tarefa fácil. Entretanto, percebe-se que a aceitação e o enfrentamento de novos papéis sociais parecem estar muito mais ligados à aceitação da gravidez do que pelo fato de serem estes pais parceiros de mulheres soropositivas para HIV.

\section{CONSIDERAÇÕES FINAIS}

A realização desta pesquisa permitiu identificar que o que levou as mulheres soropositivas para o HIV e seus companheiros a decidir engravidar, mesmo conhecendo o risco da contaminação do bebê e do companheiro, foi o forte desejo do exercício da maternidade e da paternidade, como forma de dar sentido às suas vidas.

Ser mãe e ser pai parece constituir um processo bastante complexo diante do HIV/AIDS, pois, além das repercussões dessa escolha, interferem neste processo os desafios impostos 
pela infecção, as sobrecargas particulares nas relações familiares e sociais, associadas à revelação ou não do diagnóstico e ao estigma associado à epidemia.

Diante de uma gestante soropositiva espera-se, e se deseja, que os profissionais de saúde abordem a questão do risco da transmissão vertical. Por outro lado, observa-se que tal tematização, ao centrar-se apenas no controle técnico, pode funcionar como um modo de desestimular ou censurar a gravidez no contexto do HIV/AIDS.

Assim, para além da profilaxia da transmissão vertical, é fundamental que os profissionais que atuam em serviços de atenção à saúde de indivíduos soropositivos sejam preparados para melhor atender e orientar homens e mulheres soropositivos quanto às questões sexuais e reprodutivas, pois os casais continuam utilizando métodos contraceptivos inadequados, tendo gestações indesejadas e não tendo a melhor evolução nas gestações desejadas.

A partir do exposto, o grande desafio do planejamento familiar no contexto do HIV/AIDS é compreender os significados que a gestação constroi na vida dos casais, produzir ações que promovam a autonomia dos sujeitos e garantir o direito à reprodução e o de construir uma família.

\section{REFERÊNCIAS}

1. Ministério da Saúde. Secretaria de Vigilância em Saúde. Programa Nacional de DST e AIDS. Plano Estratégico do Programa Nacional de DST/AIDS - 2004/2007. Brasília, DF: O Ministério; 2004.

2. Ministério da Saúde [homepage na internet]. Boletim Epidemiológico DST-AIDS. [acesso em10 dez 2008]. Disponível em: < http://www.aids.gov.br/data/documents/stored Documents/\% 7BB8EF5DAF-23AE-4891-AD36-1903553 A $3174 \%$ 7D/\% 7B B 8D4F426-39D3-4D08-953F61DEF2D4E657\%7D/Boletim2008_jornalistas-ok.pdf>.

3. Galvão MTG, Cerqueira ATAR, Marcondes-Machado J. Medidas contraceptivas e de proteção da transmissão do HIV por mulheres com HIV/Aids. Rev Saúde Pública 2004;38(2):194-200.

4. Jiménez AL, Gotlieb SLD, Hardy E, Zaneveld LJD. Prevenção de doenças sexualmente transmissíveis em muIheres: associação com variáveis sócio-econômicas e demográficas. Cad Saúde Pública 2001;17(1):55-62.

5. Santos NJS, Buchalla CM, Fillipe EV, Bugamelli L, Garcia S, Paiva V. Mulheres HIV positivas, reprodução e sexualidade. Rev Saúde Pública 2002;36(4)Supl 0:12-23.

6. Maldonado MT, Dickstein J, Nahoum JC. Nós estamos grávidos. 10 ed. São Paulo: Saraiva; 1997.

7. Paiva V, Lima TN, Santos N, Ventura-Filipe E, Segurado A. Sem direito de amar? A vontade de ter filhos entre homens (e mulheres) vivendo com HIV. Psciol USP 2002;13(2):105-33.

8. Ministério da Saúde. Secretaria de Atenção à Saúde. Departamento de Ações Programáticas Estratégicas. Área Técnica de Saúde da Mulher. Direitos Sexuais e Direitos Reprodutivos: uma prioridade do governo. Brasília, DF: O Ministério; 2005.
9. Minayo MCS, organizador. Pesquisa social: teoria, método e criatividade. 24 ed. Petrópolis: Vozes; 2004.

10. Guizzo BS, Krziminski CO, Oliveira DLLC. O software QSR NVivo 2.0 na análise qualitativa de dados: ferramenta para a pesquisa em ciências humanas e da saúde. Rev Gaúch Enferm 2003;24(1):53-60.

11. Carvalho FT, Piccinini CA. Aspectos históricos do feminino e do maternal e a infecção pelo HIV em mulheres. Ciênc Saúde Coletiva 2008;13(6):1889-98.

12. Sunderland A. Influência da infecção pelo vírus da imunodeficiência humana das decisões reprodutivas. In: Minkoff H H. Clínicas obstétricas e ginecológicas da América do Norte. Rio de Janeiro: Interlivros; 1990. p.567-76.

13. Gonçalves TR, Piccinini CA. Aspectos psicológicos da gestação e da maternidade no contexto da infecção pelo HIV/Aids. Psicol USP 2007;18(3):113-42.

14. Azevedo AF, Guilhem D. A vulnerabilidade da gestante na situação conjugal de soro diferença para o HIV/Aids. DST J Bras Doenças Sex Transm. 2005;17(3):189-96.

15. Coelho DF, Motta MGC. A compreensão do mundo vivido pelas gestantes portadoras do vírus da imunodeficiência humana (HIV). Rev Gaúcha Enferm 2005;26(1):31-41.

16. Carvalho FT, Piccinini CA. Maternidade em situação de infecção pelo HIV: um estudo sobre os sentimentos de gestantes. Interações em Psicologia 2006;10(2);345-55.

17. Araújo MAL, Silveira CB, Silveira CB, Melo SP. Vivências de gestantes e puérperas com o diagnóstico do HIV. Rev Bras Enferm 2008;61(5):589-94.

18. Faustino e Freitas WM, Coelho EAC, Silva ATMC. Sentir-se pai: a vivência masculina sob o olhar de gênero. Cad Saúde Pública 2007;23(1):137-45. 